\title{
Carotid Atherosclerosis and a Reduced Likelihood for Lowered Cognitive Performance in a Canadian First Nations Population
}

\author{
J.H. Fergenbaum ${ }^{a} \quad$ S. Bruce ${ }^{b} \quad$ J.D. Spence ${ }^{c} \quad$ W. Lou ${ }^{a} \quad$ A.J.G. Hanley ${ }^{a}$ \\ C. Greenwood ${ }^{\mathrm{a}}$ T.K. Young ${ }^{\mathrm{a}}$ \\ a University of Toronto, Toronto, Ont., ${ }^{b}$ University of Manitoba, Winnipeg, Man., and ' University of Western Ontario, \\ London, Ont., Canada
}

\section{Key Words}

Cognitive function - Executive function - Carotid stenosis ·

Anthropometric risk factors $\cdot$ Native Americans

\begin{abstract}
Background: We investigated the associations among cardiovascular risk factors, carotid atherosclerosis and cognitive function in a Canadian First Nations population. Methods: Individuals aged $\geq 18$ years, without stroke, nonpregnant and with First Nations status were assessed by the Trail Making Test Parts A and B. Results were combined into a Trail Making Test executive function score (TMT-exec). Doppler ultrasonography assessed carotid stenosis and plaque volume. Anthropometric, vascular and metabolic risk factors were assessed by interview, clinical examinations and blood tests. Results: For 190 individuals with TMT-exec scores, the median age of the population was 39 years. Compared to the reference group, individuals with elevated levels of left carotid stenosis (LCS) and total carotid stenosis (TCS) were less likely to demonstrate lowered cognitive performance [LCS, odds ratio (OR): $0.47,95 \%$ confidence interval (Cl): $0.24-0.96$; TCS, OR: $0.40,95 \%$ Cl: $0.20-0.80]$. No effect was shown for plaque volume. In structural equation modeling, we found that for every 1-unit change in the anthropometric factor in $\mathrm{kg} / \mathrm{m}^{2}$, there was a 0.86 -fold decrease in the percent of TCS
\end{abstract}

( $p<0.05)$. Conclusions: Individuals with elevated levels of LCS and TCS were less likely to demonstrate lowered performance. There was some suggestion that TCS mediates the effect of anthropometric risk factors on cognitive function.

Copyright $\odot 2009$ S. Karger AG, Basel

\section{Introduction}

An aging population is associated with an increased frequency of cognitive decline and dementia [1]. An early indication of cognitive decline and dementia is lowered performance on tests of executive function $[2,3]$, however, measurement of executive function in predementia disorders is still developing [4]. The association between a number of cardiovascular risk factors measured at midlife and diseases of cognition in late life suggests a common mediating biological mechanism, such as the apolipoprotein E $\varepsilon 4$ allele [5]. The role for small platelet aggregates or cholesterol microemboli shed from atherosclerotic lesions in the carotid arteries implicated among symptomatic and asymptomatic individuals in the etiology of stroke [6] may also affect cognitive function. Atherosclerosis is a systemic vascular disease of the arteries that develops through an insidious process, is initiated during early adolescence and requires prolonged expo-

\section{KARGER}

Fax +41613061234 E-Mail karger@karger.ch www.karger.com
(C) 2009 S. Karger AG, Base

0251-5350/09/0334-0321\$26.00/0

Accessible online at:

www.karger.com/ned
Jennifer H. Fergenbaum, MSc

Dalla Lana School of Public Health, University of Toronto, Health Sciences Building 155 College Street

Toronto, Ont. M5T 3M7 (Canada)

Tel. +1 416558 1219, Fax +1 416978 8299, E-Mail jennifer.fergenbaum@ utoronto.ca 
sure to predisposing factors [7]. It is not known whether cardiovascular risk factors exert their effects on cognitive function by mechanisms involving carotid atherosclerosis [8]. Recent studies have linked carotid atherosclerosis with a number of anthropometric, vascular [9-11], and metabolic [12-14] risk factors. In epidemiological studies, the relationship between carotid atherosclerosis and cognitive decline and dementia remains unclear. Two large reviews on the relationship could not provide a definite conclusion due to a number of methodological limitations including the use of symptomatic populations, lack of a control group and poorly characterized measures of atherosclerosis [15], and lack of a well-defined study population [16]. Recent investigations have also been limited in that they have not included cardiovascular risk factors as confounders in their multivariable analysis [17-19]. Only one previous study had information on cardiovascular risk factors, carotid atherosclerosis and cognitive function. In this study, carotid stenosis was associated with an approximately 7 -fold increased risk for cognitive impairment [20].

The objectives of this study were to investigate the interrelationships between cardiovascular risk factors, carotid atherosclerosis and cognitive function in a Canadian First Nations population. The First Nations population experiences a larger proportion of deleterious risk factors and chronic disease compared to their Canadian counterparts [21] strengthening the ability to detect associations, if they exist. We hypothesize that an increased burden of carotid atherosclerosis would be associated with an increased risk for lowered cognitive performance and that carotid atherosclerosis mediates the effect of anthropometric risk factors on cognitive function.

\section{Materials and Methods}

This was a cross-sectional study conducted in a road-accessible Plains Ojibwa First Nations community in southern Manitoba, Canada. Eligible individuals were community residents 18 years of age or older, without stroke, nonpregnant, and designated with First Nations status. Recruitment occurred through home visits to each home in the community without sampling and advertisements in the local Health Center newsletter. All eligible community members were invited to participate. Demographic, anthropometric, vascular, and metabolic data were collected as part of a larger cross-sectional study on diabetes and diabetes complications [22]. After exclusions, there were 510 eligible individuals. Measures of carotid atherosclerosis and cognitive function were assessed among a subset of the participants in the context of another cross-sectional study on this population. Cognitive tests were administered by two graduate student research assistants at the research study site. A total of 190 individuals completed the Trail Making Test Parts A and B, a majority of whom $(n=148)$ had information on risk factors and carotid atherosclerosis, therefore the study population was limited by the number of individuals who had also completed the cognitive tests. The study was approved by the Human Ethics Boards of the University of Manitoba and the University of Toronto. The study was conducted with the approval of, and in partnership with, the particular First Nation community. Individuals who participated provided informed consent.

The Trail Making Test Parts A and B were administered according to standard protocols [23]. A measure of executive function was calculated $[(\mathrm{B}-\mathrm{A}) / \mathrm{A}][24]$, which we designated the Trail Making Test executive function score (TMT-exec). Those with TMT-exec $\geq 2.33$ were classified as having lowered cognitive performance [TMT-exec(+)], whereas individuals with TMT-exec $<2.33$ were classified as not having lowered cognitive performance [TMT-exec(-)]. The cutoff point was determined from preliminary analyses in which the distribution of TMT-exec was bimodal (data not shown).

For carotid plaque volume, a series of parallel two-dimensional images were collected and used to reconstruct a three-dimensional image $[25,26]$. Values for the right and left sides of the neck were determined in millimeters cubed and total plaque volume was calculated as the sum of both sides. Peak systolic velocity of the right and left internal carotid arteries was used to estimate the percent stenosis [27]. Percent carotid stenosis was determined for the right and left sides of the neck and total carotid stenosis was calculated as the sum of both sides.

Information on risk factors was ascertained through clinical examination and in-person questionnaires administered by trained personnel. Hypertension was defined as systolic blood pressure $\geq 130 \mathrm{~mm} \mathrm{Hg}$ and/or diastolic blood pressure $\geq 85 \mathrm{~mm}$ $\mathrm{Hg}$ [28]. Self-report of at least one of the following was used to define a previous history of cardiovascular disease: angina, history of angioplasty or revascularization, myocardial infarction, and peripheral arterial disease. Weight and height were collected and used to calculate the BMI. Individuals were classified as obese if their BMI was $\geq 30$ [29]. Waist circumference was determined at the level of noticeable waist narrowing using an inelastic tape measure. For individuals in whom waist narrowing was difficult to identify, an indeterminate waist was approximated by taking the girth at the estimated lateral level of the twelfth or lower floating rib. An increased waist circumference and the presence of dyslipidemia were defined according to standard criteria [28]. Fasting venous blood samples were collected, stored at $-20^{\circ} \mathrm{C}$ and analyzed for triglycerides, cholesterol, high- and low-density lipoproteins, glucose, insulin, and total homocysteine. Insulin resistance was examined by the homeostasis model of assessment [30], and ever having smoked and duration of smoking from selfreports.

The proportion of individuals classified as having lowered cognitive performance was examined. For risk factor information and carotid atherosclerosis, individuals lacking complete data for specific variables were reassigned a value for each variable. Continuous variables were assigned to the mean value from among the total eligible population $(n=510)$, except where the mean and median values were quite different in which case the median value was assigned. Descriptive statistics and risk estimates using this approach for handling missing data were compared to the strategy of deleting individuals with incomplete information. The 


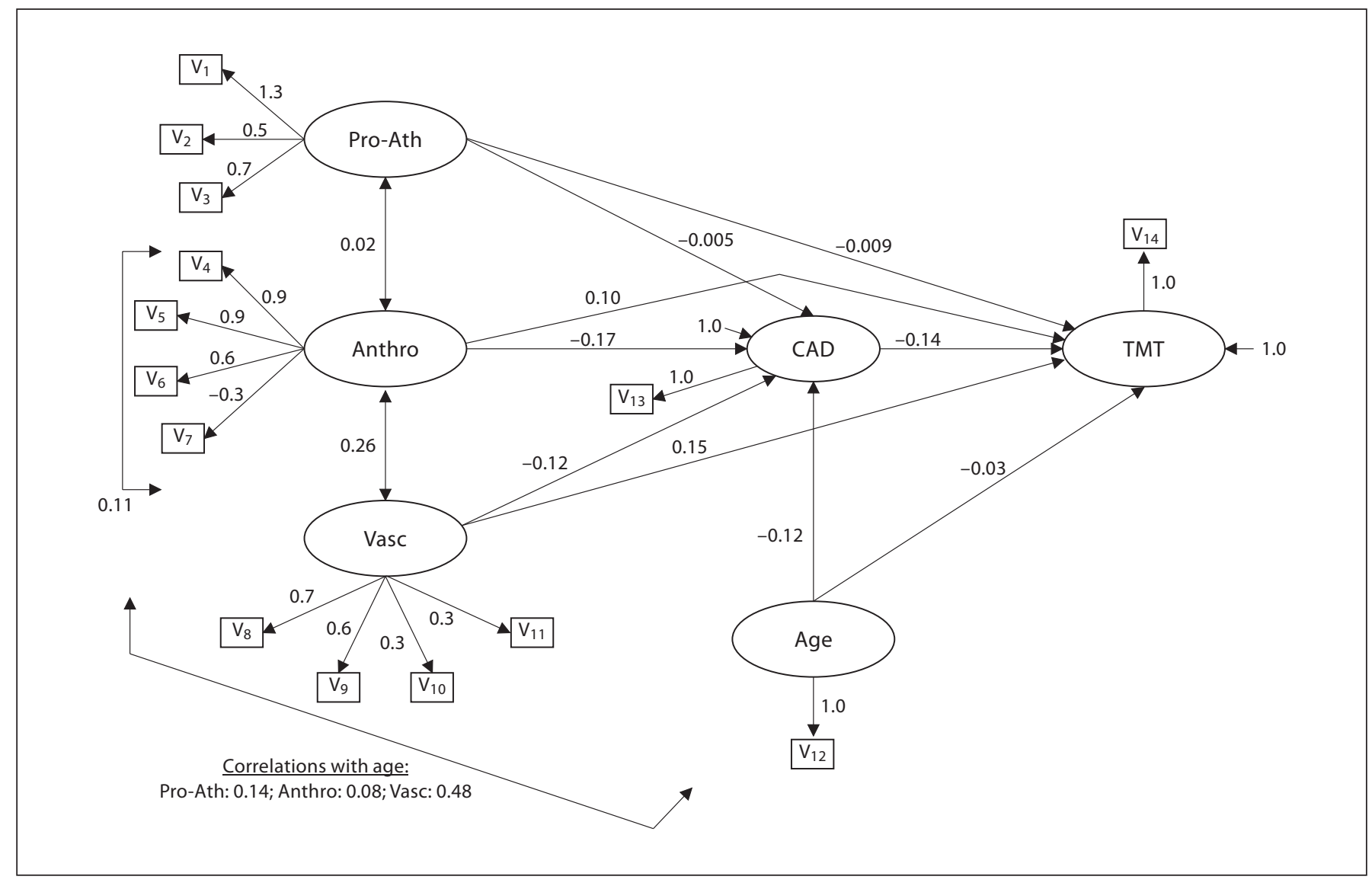

Fig. 1. SEM model. $V_{1}=$ Cholesterol; $V_{2}=$ triglycerides; $V_{3}=$ low-density lipoprotein; $V_{4}=B M I ; V_{5}=$ waist circumference; $\mathrm{V}_{6}=$ insulin resistance; $\mathrm{V}_{7}=$ high-density lipoprotein; $\mathrm{V}_{8}=$ systolic blood pressure; $\mathrm{V}_{9}=$ diastolic blood pressure; $\mathrm{V}_{10}=$ smoking duration; $\mathrm{V}_{11}=$ homocysteine; $\mathrm{V}_{12}=$ age; $\mathrm{V}_{13}=$ TCS (CAD); $\mathrm{V}_{14}=$ TMT-exec; Pro-Ath = proatherogenic; Anthro = anthropometric; Vasc = vascular.

results were similar and the former was used for subsequent analyses. For categorical variables, individuals were assigned to the reference group. For descriptive analyses, each continuous variable was examined for its distribution and normality, and nonnormal variables were log-transformed using the natural logarithm, when appropriate, for the structural equation modeling (SEM) analysis. Descriptive analysis showed similar results for smoking duration when those who never smoked were assigned a smoking duration of zero years compared to those assigned to the mean value from among the total population, with the latter used for subsequent analysis and log-transformed for SEM analysis. Unadjusted odds ratios (ORs) with corresponding 95\% confidence intervals (CIs) were calculated using logistic regression to examine the associations between categories of carotid atherosclerosis and TMT-exec. Categories of risk factors were also examined in unadjusted analysis. Categories were based on cutoff points according to standard criteria (e.g. BMI $\geq 30$ for obese) or the median value among TMT-exec(-) individuals (e.g. carotid measures), as determined from preliminary analysis. Multivariable logistic regression models were used to examine the associa- tions between right (RCS), left (LCS) and total (TCS) carotid stenosis and right, left and total plaque volume and TMT-exec, while accounting for confounding variables that have been identified in the literature. Potential confounders included hypertension, a history of cardiovascular disease, dyslipidemia, obesity, insulin resistance, diabetes, homocysteine, and ever having smoked. Statistical models were built for the right and left sides and the total, with age and sex considered in all models. Multivariable models were used to calculate the adjusted ORs, 95\% CIs and p values.

An SEM analysis was conducted to examine the a priori specified network of interrelationships between cardiovascular risk factors, TCS and TMT-exec as shown in an SEM model (fig. 1). This multivariate modeling technique is a useful tool that allows complex theoretical relationships to be statistically modeled [31, 32]. Path coefficients and factor loadings with their corresponding standard errors and $p$ values were determined for the SEM model. $\chi^{2}$ statistics were reviewed to examine model fit. Power calculations were performed and the model was overidentified. The latent variables included in the model and labeled as anthropometric, proatherogenic and vascular were predetermined using 
Table 1. Descriptive characteristics $(n=190)$

\begin{tabular}{|c|c|c|c|c|c|c|}
\hline & Mean & $\mathrm{SD}$ & Median & IQR & Range & Percent \\
\hline Age, years & 38.8 & 9.9 & 38.5 & 12 & $19-66$ & - \\
\hline Sex (female) & - & - & - & - & - & 53.7 \\
\hline Systolic blood pressure, $\mathrm{mm} \mathrm{Hg}$ & 127.9 & 15.7 & 127.7 & 12 & $92-200$ & \\
\hline Diastolic blood pressure, $\mathrm{mm} \mathrm{Hg}$ & 76.1 & 8.4 & 76.4 & 9 & 58-106 & \\
\hline $\mathrm{BMI}, \mathrm{kg} / \mathrm{m}^{2}$ & 32.5 & 7 & 31.5 & 9.8 & $19.2-53.3$ & - \\
\hline Waist circumference, $\mathrm{cm}$ & 105.4 & 15.7 & 104 & 23 & $67-150$ & - \\
\hline Insulin resistance, units & 6.2 & 7.3 & 4.5 & 5.2 & $0.5-67.4$ & - \\
\hline Triglycerides, $\mathrm{mmol} / \mathrm{l}$ & 2.2 & 1.7 & 1.7 & 1 & $0.4-11.3$ & - \\
\hline Cholesterol, $\mathrm{mmol} / \mathrm{l}$ & 5 & 1.1 & 4.9 & 1 & $2.2-8.4$ & - \\
\hline High-density lipoprotein, mmol/l & 1.2 & 0.3 & 1.2 & 0.2 & $0.6-2.5$ & - \\
\hline Low-density lipoprotein, $\mathrm{mmol} / \mathrm{l}$ & 2.8 & 0.8 & 2.8 & 0.5 & $0.8-5.9$ & - \\
\hline Smoking duration, years & 16.3 & 8 & 16.1 & 10 & $1-40$ & - \\
\hline Homocysteine, $\mu \mathrm{mol} / \mathrm{l}$ & 8.9 & 2.9 & 8.9 & 1.7 & $4.5-30$ & - \\
\hline Right carotid stenosis, \% & 21 & 9.3 & 20 & 2.5 & $0-50$ & - \\
\hline Left carotid stenosis, $\%$ & 22 & 10 & 22.7 & 20 & $0-50$ & - \\
\hline Total carotid stenosis, \% & 41.8 & 16.7 & 40 & 20 & $0-100$ & - \\
\hline Right plaque volume, $\mathrm{mm}^{3}$ & 9.9 & 15.8 & 4.6 & 8.6 & $0-112.4$ & - \\
\hline Left plaque volume, $\mathrm{mm}^{3}$ & 7.3 & 8.7 & 4.6 & 5.9 & $0-51.6$ & - \\
\hline Total plaque volume, $\mathrm{mm}^{3}$ & 17.5 & 19.8 & 11.4 & 11.6 & $0-133.1$ & - \\
\hline
\end{tabular}

$\mathrm{SD}=$ Standard deviation

a data-driven approach of principal components analysis and a promax rotation according to standard guidelines [32]. The amount of mediation was determined from two different SEM models [33]. All analyses were calculated in SAS v. 9.1 (SAS Institute, Cary, N.C., USA).

\section{Results}

The descriptive characteristics are shown in table 1. The median age of the sample was 38.5 years and $54 \%$ were female. Except for waist circumference, all risk factors were non-normally distributed. Overall, the data indicated that while the median values were not exceptional, the range of values exceeded optimal levels according to standard criteria [29]; for example, BMI was as high as 53.3. Examining the median and interquartile range (IQR) for RCS and LCS suggested mild stenosis (RCS: 21.0, IQR: 9.3\%; LCS: 22.0, IQR: 10.0\%), and for TCS, moderate stenosis (TCS: 41.8, IQR: 16.7\%) [6].

There were 72 individuals who were classified as TMT$\operatorname{exec}(+)(37.9 \%)$, while 118 individuals were classified as TMT-exec(-) (62.1\%). Table 2 shows the unadjusted ORs for risk factors and carotid atherosclerosis in relation to TMT-exec. Individuals classified as having LCS of $\geq 22.7 \%$ were less likely to demonstrate lowered cognitive performance compared to those with LCS of $<22.7 \%$ (unadjusted OR: 0.47, 95\% CI: 0.26-0.85). A similar effect was shown for TCS, where individuals classified as having TCS of $\geq 40 \%$ were less likely to demonstrate lowered cognitive performance compared to those with TCS of <40\% (OR: 0.35, 95\% CI: 0.19-0.67). There were no effects for RCS or plaque volume. Among TMT-exec(-), there were a number of individuals with TCS values defined by the $40 \%$ cutoff point. When we changed who was included in the reference group and examined the association for TCS of $>40 \%$ compared to those with TCS of $\leq 40 \%$, there was no effect. For the covariates, those classified as obese had a 3-fold increased risk for lowered cognitive performance (OR: 3.02, 95\% CI: 1.57-5.81). Increased waist circumference was the only other risk factor that was significantly associated with the outcome (OR: 2.97, 95\% CI: 1.44-6.13).

Table 3 shows the multivariable ORs for RCS, LCS and TCS and TMT-exec. Individuals with elevated levels of LCS and TCS were less likely to demonstrate lowered cognitive performance (LCS, OR: 0.47, 95\% CI: 0.24-0.96; TCS, OR: 0.40, 95\% CI: 0.20-0.80). There were no effects for RCS. There were also no effects for plaque volume (data not shown). 
Table 2. Unadjusted ORs and $95 \%$ CIs for risk factors and carotid atherosclerosis with TMT-exec

\begin{tabular}{|c|c|c|c|}
\hline Covariates & $\begin{array}{l}\text { TMT-exec(+) } \\
(\mathrm{n}=72)\end{array}$ & $\begin{array}{l}\text { TMT-exec(-) } \\
(\mathrm{n}=118)\end{array}$ & OR (95\% CI) \\
\hline \multicolumn{4}{|l|}{ Age } \\
\hline$<35$ years & 22 & 33 & 1.00 \\
\hline 35-44 years & 29 & 59 & $0.74(0.37-1.48)$ \\
\hline $45-54$ years & 16 & 19 & $1.26(0.54-2.97)$ \\
\hline $55+$ years & 5 & 7 & $1.07(0.30-3.81)$ \\
\hline \multicolumn{4}{|l|}{ Sex } \\
\hline Males & 27 & 61 & 1.00 \\
\hline Females & 45 & 57 & $1.78(0.98-3.24)$ \\
\hline \multicolumn{4}{|l|}{ Hypertension } \\
\hline No & 61 & 110 & 1.00 \\
\hline Yes & 11 & 8 & $2.48(0.95-6.49)$ \\
\hline \multicolumn{4}{|c|}{ History of cardiovascular disease } \\
\hline No & 60 & 103 & 1.00 \\
\hline Yes & 12 & 15 & $1.37(0.60-3.13)$ \\
\hline \multicolumn{4}{|l|}{ Dyslipidemia } \\
\hline No & 13 & 30 & 1.00 \\
\hline Yes & 59 & 88 & $1.55(0.75-3.21)$ \\
\hline \multicolumn{4}{|l|}{ Obese } \\
\hline No & 17 & 57 & 1.00 \\
\hline Yes & 55 & 61 & $3.02(1.57-5.81)^{*}$ \\
\hline \multicolumn{4}{|l|}{ Ever smoked } \\
\hline No & 22 & 40 & 1.00 \\
\hline Yes & 50 & 78 & $1.17(0.62-2.19)$ \\
\hline \multicolumn{4}{|c|}{ Right carotid stenosis } \\
\hline$<22.5 \%$ & 46 & 58 & 1.00 \\
\hline$\geq 22.5 \%$ & 26 & 60 & $0.55(0.30-1.00)$ \\
\hline \multicolumn{4}{|c|}{ Left carotid stenosis } \\
\hline$<22.7 \%$ & 44 & 50 & 1.00 \\
\hline$\geq 22.7 \%$ & 28 & 68 & $0.47(0.26-0.85)^{*}$ \\
\hline \multicolumn{4}{|c|}{ Total carotid stenosis } \\
\hline$<40.0 \%$ & 32 & 26 & 1.00 \\
\hline$\geq 40.0 \%$ & 40 & 92 & $0.35(0.19-0.67)^{*}$ \\
\hline \multicolumn{4}{|c|}{ Right plaque volume } \\
\hline$<4.6 \mathrm{~mm}^{3}$ & 24 & 40 & 1.00 \\
\hline$\geq 4.6 \mathrm{~mm}^{3}$ & 48 & 78 & $1.03(0.55-1.91)$ \\
\hline \multicolumn{4}{|c|}{ Left plaque volume } \\
\hline$<4.6 \mathrm{~mm}^{3}$ & 29 & 42 & 1.00 \\
\hline$\geq 4.6 \mathrm{~mm}^{3}$ & 43 & 76 & $0.82(0.45-1.50)$ \\
\hline \multicolumn{4}{|c|}{ Total plaque volume } \\
\hline$<11.4 \mathrm{~mm}^{3}$ & 24 & 46 & 1.00 \\
\hline$\geq 11.4 \mathrm{~mm}^{3}$ & 48 & 72 & $1.28(0.69-2.36)$ \\
\hline
\end{tabular}

Table 4 shows the SEM results for the interrelationships between cardiovascular risk factors, TCS and TMT-exec. All variables were log-transformed except age, TMT-exec and TCS. The $\chi^{2}$ statistic for model 1 was 234.3 ( $\mathrm{p}<0.0001)$ and for model 2 , it was 256.5 ( $\mathrm{p}<$
Table 3. Multivariable adjusted ORs and $95 \%$ CIs for carotid stenosis and TMT-exec

\begin{tabular}{|c|c|c|}
\hline & OR (95\% CI) & $\mathrm{p}$ value \\
\hline \multicolumn{3}{|l|}{ Right carotid stenosis } \\
\hline Age & $1.00(0.97-1.03)$ & 0.9321 \\
\hline Sex & $1.67(0.88-3.17)$ & 0.1194 \\
\hline Right carotid stenosis & $0.61(0.30-1.24)$ & 0.1739 \\
\hline Hypertension & $2.27(0.80-6.42)$ & 0.1236 \\
\hline CVD & $1.21(0.50-2.94)$ & 0.6743 \\
\hline Obesity & $2.46(1.25-4.84)$ & 0.0093 \\
\hline Ever smoked & $0.81(0.38-1.72)$ & 0.5837 \\
\hline \multicolumn{3}{|l|}{ Left carotid stenosis } \\
\hline Age & $1.00(0.97-1.04)$ & 0.9010 \\
\hline Sex & $1.87(0.97-3.62)$ & 0.0625 \\
\hline Left carotid stenosis & $0.47(0.24-0.96)$ & 0.0368 \\
\hline Hypertension & $2.20(0.77-6.29)$ & 0.1399 \\
\hline CVD & $1.13(0.46-2.79)$ & 0.7919 \\
\hline Obesity & $2.30(1.16-4.56)$ & 0.0173 \\
\hline Ever smoked & $0.73(0.35-1.55)$ & 0.4182 \\
\hline \multicolumn{3}{|l|}{ Total carotid stenosis } \\
\hline Age & $1.00(0.97-1.03)$ & 0.9084 \\
\hline Sex & $1.68(0.88-3.23)$ & 0.1193 \\
\hline Total carotid stenosis & $0.40(0.20-0.80)$ & 0.0092 \\
\hline Hypertension & $2.05(0.71-5.90)$ & 0.1847 \\
\hline CVD & $1.17(0.47-2.90)$ & 0.7431 \\
\hline Obesity & $2.38(1.20-4.72)$ & 0.0129 \\
\hline Ever smoked & $0.83(0.41-1.68)$ & 0.5973 \\
\hline
\end{tabular}

Age is a continuous variable. The remaining variables are categorical as in table 2. CVD = History of cardiovascular disease. The $\mathrm{p}$ values in italics are significant.

0.0001), suggesting that our theoretical model was not consistent with our dataset. In model 1, no factor was associated with TMT-exec. For TMT-exec in model 2, no associations were shown. For TCS in model 2, the anthropometric factor was associated with a decrease (0.86 times, $\mathrm{p}<0.05)$ in the percent of TCS. Therefore, for every 1-unit change in the anthropometric factor standardized to $\mathrm{kg} / \mathrm{m}^{2}$, there was a 0.86 -fold decrease in the percent of TCS when adjusted for age, and proatherogenic and vascular factors. No other factor was associated with TCS. Factor loadings were similar in magnitude and significant across models. The total effect of the anthropometric factor on TMT-exec was $65 \%$ and the amount of mediation was $31 \%$, though not all path coefficients were significant. No modifications were performed. The final model with standardized estimates is shown in figure 1. 
Table 4. Structural equation models

\begin{tabular}{|c|c|c|}
\hline \multirow[t]{2}{*}{ Path models } & \multicolumn{2}{|l|}{ Path coefficients } \\
\hline & model 1 & model 2 \\
\hline \multicolumn{3}{|l|}{ TMT-exec } \\
\hline Age & $0.02 \pm 0.04$ & $-0.003 \pm 0.009$ \\
\hline Anthropometric & $0.84 \pm 0.78$ & $0.53 \pm 0.42$ \\
\hline Proatherogenic & $0.06 \pm 0.17$ & $0.03 \pm 0.17$ \\
\hline Vascular & $-3.26 \pm 11.73$ & $1.82 \pm 1.29$ \\
\hline TCS & - & $-0.14 \pm 0.08$ \\
\hline \multicolumn{3}{|l|}{ TCS } \\
\hline Age & - & $-0.01 \pm 0.009$ \\
\hline Anthropometric & - & $-0.86 \pm 0.40^{*}$ \\
\hline Proatherogenic & - & $-0.02 \pm 0.17$ \\
\hline Vascular & - & $-1.44 \pm 1.39$ \\
\hline \multirow[t]{2}{*}{ Measurement models } & \multicolumn{2}{|l|}{ Factor loadings } \\
\hline & model 1 & model 2 \\
\hline \multicolumn{3}{|l|}{ Anthropometric } \\
\hline BMI & 1.00 & 1.00 \\
\hline Waist circumference & $0.71 \pm 0.04^{* * *}$ & $0.72 \pm 0.04^{* * *}$ \\
\hline Insulin resistance & $2.69 \pm 0.25^{* * *}$ & $2.70 \pm 0.26^{* * *}$ \\
\hline High-density lipoprotein & $-0.35 \pm 0.08^{* * *}$ & $-0.36 \pm 0.08^{* * *}$ \\
\hline \multicolumn{3}{|l|}{ Proatherogenic } \\
\hline Cholesterol & 1.00 & 1.00 \\
\hline Triglycerides & $0.93 \pm 0.18^{* * *}$ & $0.94 \pm 0.18^{* * *}$ \\
\hline Low-density lipoprotein & $0.72 \pm 0.10^{* * *}$ & $0.72 \pm 0.10^{* * *}$ \\
\hline \multicolumn{3}{|l|}{ Vascular } \\
\hline Systolic blood pressure & 1.00 & 1.00 \\
\hline Diastolic blood pressure & $0.57 \pm 0.23^{*}$ & $0.73 \pm 0.15^{* * *}$ \\
\hline Smoking duration & $9.40 \pm 2.21^{* * *}$ & $2.14 \pm 0.75^{* *}$ \\
\hline Homocysteine & $1.65 \pm 0.57^{* *}$ & $0.82 \pm 0.28^{* *}$ \\
\hline
\end{tabular}

${ }^{*} \mathrm{p}<0.05 ;{ }^{* *} \mathrm{p}<0.01 ;{ }^{* * *} \mathrm{p}<0.001$. Results are estimates \pm standard error. Estimates shown are not standardized.

\section{Discussion}

Our study found that individuals with elevated levels of LCS and TCS were less likely to demonstrate lowered performance on a test of executive function suggesting that carotid stenosis is not detrimental to cognitive functioning. The role of TCS in cognitive functioning may additionally include acting as a mediator, whereby anthropometric risk factors affect the levels of TCS, which in turn have the potential to influence cognitive functioning.

This study showed that higher levels of LCS and TCS were associated with a decreased likelihood for lowered cognitive performance of an executive origin. The ab- sence of an association between carotid measures and the Trail Making Test Part A also suggests that the results for TMT-exec are attributed to executive function and not processing speed. The Cardiovascular Heart Study is the only previous study that also had detailed information on carotid atherosclerosis, cardiovascular risk factors and cognitive function [20]. For the cross-sectional component, they showed that LCS of $\geq 75 \%$ was associated with an approximately 7-fold increased risk for cognitive impairment in multivariable analysis. This study differs from ours in the use of no stenosis as the reference group, a higher cutoff point, an older population, and a global measure of cognitive function (i.e. MMSE). In our study, there was only 1 individual with zero TCS and only 8 individuals with TCS above $80 \%$. Information for both sides of the neck suggested that the effect shown for TCS was predominately accounted for by LCS. The lack of consistent results between carotid stenosis and plaque volume was expected given their weak correlation. Also contributing to the different results is the advanced nature of stenosis compared to plaque volume [34].

We anticipated that increased levels of carotid atherosclerosis would be associated with an increased risk for lowered cognitive performance. Our results therefore are contradictory to our a priori hypothesis. One reason we observed the opposite effect may be due to the phenomenon of compensatory vessel enlargement, where up to $40 \%$ of stenosis, the lumen area and the vessel wall increase to maintain a normal diameter in response to increases in plaque [35]. In our study population, carotid stenosis values at or slightly above this threshold may be better at triggering compensatory enlargement than lower values and may explain why no effect was shown for TCS of $>40 \%$ relative to $\leq 40 \%$, compared to $\geq 40 \%$ relative to $<40 \%$. Also contributing to the paradoxical results is the youthfulness of our study population, which precluded individuals with severe stenosis ( $\geq 75 \%)$ and those who would be symptomatic. Inclusion of a predominately asymptomatic study population suggests that our results are consistent with the notion that individuals with mild to moderate stenosis may have a healthier vascular microenvironment than individuals with higher values, and therefore they would be expected to perform better on tests of cognitive function of an executive origin. Ageassociated changes in brain structure and function beginning at midlife with concomitant effects shown for midlife cardiovascular risk factors on diseases of cognition in late life highlight the presence of a latency effect, with their interrelationships across the life course not known [5]. Had we conducted a longitudinal study with 
an increasing aging population, an association between moderate to severe levels of carotid stenosis and an increased risk for lowered cognitive performance may have been detected. Although our results were in the opposite direction from anticipated, our study supports the role of vascular factors and disease in cognitive function of an executive origin.

The associations shown for the anthropometric risk factors were varied depending on the outcome involved and may have resulted due to a number of methodological reasons. First, our observation that the anthropometric factor was negatively associated with TCS is in contrast to previous findings that showed a positive association [11]. Reasons include the use of different measures of atherosclerosis, which reflect different stages of the disease [36]. Excess adiposity may have a role in the very early stages of atherosclerosis such as with intima-media thickness and not carotid stenosis due to the inflammatory effects of adipokines [37]. Second, the First Nations population provided unique data, unlike previous studies. As in other First Nations populations in Canada undergoing rapid socioeconomic and lifestyle changes leading to increasingly prevalent health problems and chronic diseases such as diabetes, this population included individuals who were extremely obese. Therefore, increased levels of BMI and lower levels of TCS resulted in an overall negative correlation in our study. Third, consistent with a number of previous studies [38], obesity and waist circumference and an increased risk for lowered cognitive performance were shown in our unadjusted analysis. Similar risks suggest the accelerated effect of an obesity milieu [39], given that the median age was 39 years in our study population. Finally, obesity influences atherosclerosis through a number of complex mechanisms including diabetes, hypertension and lipoproteins [37], therefore alternative SEM models may be needed.

This study has several limitations, including the absence of information on past history of traumatic brain injury [40], psychiatric [41], or depressive conditions [42], and alcohol use [43] that may affect cognitive functioning. Additionally, we did not have information on statin use. Temporality is an issue when using a cross-sectional design to examine etiology, though the influence of lowered cognitive performance on carotid stenosis is unlikely. Limitations to the generalizability of the results include the social and cultural context of the Manitoba First Nations population. Analysis of times to completion for Part A of the Trail Making Test with age was consistent with normative data [44], suggesting that our sample is representative. However, in comparison to a similarly aged population, times for Trail Making Test Part B were slightly higher, indicating that our volunteer sample may be less healthy [45]. There is no normative data for TMTexec.

\section{Conclusion}

In conclusion, this study showed that individuals with elevated levels of LCS and TCS were less likely to demonstrate lowered cognitive performance. Our results do not support the hypothesis of carotid atherosclerosis being associated with an increased risk for lowered cognitive performance. However, given a plausible biological mechanism, our results support the role of vascular factors and disease in cognitive function of an executive origin. Also, this study showed that anthropometric risk factors were associated with a decrease in the percent of TCS but an increased risk for lowered cognitive performance. Our findings highlight the importance of careful consideration when examining complex biological relationships.

\section{Acknowledgements}

Funding for the study was provided by the Canadian Institutes of Health Research (CRT-43825, PI: Kue Young) and the Canadian Stroke Network (PI: Sharon Bruce). Jennifer H. Fergenbaum is the recipient of a Canadian Institute of Health Research doctoral award.

References

1 Qiu C, De Ronchi D, Fratiglioni L: The epidemiology of the dementias: an update. Curr Opin Psychiatry 2007;20:380-385.

$\checkmark 2$ Moorhouse P, Rockwood K: Vascular cognitive impairment: current concepts and clinical developments. Lancet Neurol 2008;7: 246-255.

3 Juby A, Tench S, Baker V: The value of the clock drawing in identifying executive dysfunction in people with a normal Mini-Mental State Examination score. CMAJ 2002;167: 859-864

4 Hachinski V, Iadecola C, Petersen RC, Breteler MM, Nyenhuis DL, Black SE, Powers WJ, DeCarli C, Merino JG, Kalaria RN, Vinters HV, Holtzman DM, Rosenberg GA, Wallin A, Dichgans M, Marler JR, Leblanc GG: National Institute of Neurological Disorders and Stroke-Canadian Stroke Network vascular cognitive impairment harmonization standards. Stroke 2006;37:2220-2241.

5 Launer LJ: The epidemiologic study of dementia: a life-long quest? Neurobiol Aging 2005;26:335-340. 
6 Norris JW, Zhu CZ: Silent stroke and carotid stenosis. Stroke 1992;23:483-485.

7 Keaney JF Jr: Atherosclerosis: from lesion formation to plaque activation and endothelial dysfunction. Mol Aspects Med 2000;21: 99-166.

$\$ 8$ Lusis AJ: Atherosclerosis. Nature 2000;407: 233-241.

-9 LiS, Chen W, Srinivasan SR, Bond MG, Tang R, Urbina EM, Berenson GS: Childhood cardiovascular risk factors and carotid vascular changes in adulthood: the Bogalusa Heart Study. JAMA 2003;290:2271-2276.

10 Raitakari OT, Juonala M, Kahonen M, Taittonen L, Laitinen T, Maki-Torkko N, Jarvisalo MJ, Uhari M, Jokinen E, Ronnemaa T, Akerblom HK, Viikari JS: Cardiovascular risk factors in childhood and carotid artery intima-media thickness in adulthood: the Cardiovascular Risk in Young Finns Study. JAMA 2003;290:2277-2283.

-11 Urbina EM, Srinivasan SR, Tang R, Bond MG, Kieltyka L, Berenson GS: Impact of multiple coronary risk factors on the intimamedia thickness of different segments of carotid artery in healthy young adults (The Bogalusa Heart Study). Am J Cardiol 2002;90: 953-958.

12 Brohall G, Oden A, Fagerberg B: Carotid artery intima-media thickness in patients with type 2 diabetes mellitus and impaired glucose tolerance: a systematic review. Diabet Med 2006;23:609-616.

13 Tzou WS, Douglas PS, Srinivasan SR, Bond MG, Tang R, Chen W, Berenson GS, Stein JH: Increased subclinical atherosclerosis in young adults with metabolic syndrome: the Bogalusa Heart Study. J Am Coll Cardiol 2005;46:457-463.

-14 Scuteri A, Najjar SS, Muller DC, Andres R, Hougaku H, Metter EJ, Lakatta EG: Metabolic syndrome amplifies the age-associated increases in vascular thickness and stiffness. J Am Coll Cardiol 2004;43:1388-1395.

15 Rao R: The role of carotid stenosis in vascular cognitive impairment. Eur Neurol 2001; 46:63-69.

16 Bakker FC, Klijn CJ, Jennekens-Schinkel A, Kappelle LJ: Cognitive disorders in patients with occlusive disease of the carotid artery: a systematic review of the literature. J Neurol 2000;247:669-676.

$\checkmark 17$ Haley AP, Forman DE, Poppas A, Hoth KF, Gunstad J, Jefferson AL, Paul RH, Ler AS, Sweet LH, Cohen RA: Carotid artery intimamedia thickness and cognition in cardiovascular disease. Int J Cardiol 2007;121:148154.

18 Mathiesen EB, Waterloo K, Joakimsen O, Bakke SJ, Jacobsen EA, Bonaa KH: Reduced neuropsychological test performance in asymptomatic carotid stenosis: the Tromso Study. Neurology 2004;62:695-701.
19 Hofman A, Ott A, Breteler MM, Bots ML, Slooter AJ, van Harskamp F, van Duijn CN, Van Broeckhoven C, Grobbee DE: Atherosclerosis, apolipoprotein $\mathrm{E}$, and prevalence of dementia and Alzheimer's disease in the Rotterdam Study. Lancet 1997;349:151-154.

20 Johnston SC, O’Meara ES, Manolio TA, Lefkowitz D, O'Leary DH, Goldstein S, Carlson MC, Fried LP, Longstreth WT Jr: Cognitive impairment and decline are associated with carotid artery disease in patients without clinically evident cerebrovascular disease. Ann Intern Med 2004;140:237-247.

21 Health Canada: A Statistical Profile on the Health of First Nations in Canada. Ottawa, First Nations and Inuit Health Branch, Health Canada, 2005.

22 Bruce SG, Young KT: Prevalence and risk factors for neuropathy in a Canadian First Nation community. Diabetes Care 2008;31: 1837-1841.

23 Reitan RM: Validity of the trail making test as an indicator of organic brain damage. Percept Mot Skills 1958;8:271-276.

24 Stuss DT, Bisschop SM, Alexander MP, Levine B, Katz D, Izukawa D: The trail making test: a study of focal lesion patients. Psychol Assess 2001;13:230-239.

25 Landry A, Spence JD, Fenster A: Measurement of carotid plaque volume by 3-dimensional ultrasound. Stroke 2004;35:864-869.

26 Landry A, Fenster A: Theoretical and experimental quantification of carotid plaque volume measurements made by three-dimensional ultrasound using test phantoms. Med Phys 2002;29:2319-2327.

27 Grant EG, Benson CB, Moneta GL, Alexandrov AV, Baker JD, Bluth EI, Carroll BA, Eliasziw M, Gocke J, Hertzberg BS, Katanick S, Needleman L, Pellerito J, Polak JF, Rholl KS, Wooster DL, Zierler RE: Carotid artery stenosis: gray-scale and Doppler US diagnosis - Society of Radiologists in Ultrasound Consensus Conference. Radiology 2003;229: 340-346.

28 Expert Panel on Detection, Evaluation, and Treatment of High Blood Cholesterol in Adults: Executive summary of the Third Report of the National Cholesterol Education Program (NCEP) Expert Panel on detection, evaluation, and treatment of high blood cholesterol in adults (Adult Treatment Panel III). JAMA 2001;285:2486-2497.

29 National Institutes of Health: Identification, evaluation and treatment of overweight and obesity in adults. NIH Publication No. 004084, 2000.

30 Wallace TM, Levy JC, Matthews DR: Use and abuse of HOMA modeling. Diabetes Care 2004;27:1487-1495.

31 Tabachnick BG, Fidell LS: Using Multivariate Statistics, ed 5. Boston, Pearson/Allyn \& Bacon, 2007.

32 Hatcher H: A Step-by-Step Approach to Using SAS for Factor Analysis and Structural Equation Modeling. Cary, SAS Press, 1994.
33 Kenny DA: Mediation. http://davidakenny. net $/ \mathrm{cm} /$ mediate.htm (accessed January 2009).

34 Golledge J, Siew DA: Identifying the carotid 'high risk' plaque: is it still a riddle wrapped up in an enigma? Eur J Vasc Endovasc Surg 2008;35:2-8.

35 Glagov S, Weisenberg E, Zarins CK, Stankunavicius R, Kolettis GJ: Compensatory enlargement of human atherosclerotic coronary arteries. N Engl J Med 1987;316: 1371-1375.

-36 Al-Shali K, House AA, Hanley AJ, Khan HM, Harris SB, Mamakeesick M, Zinman B, Fenster A, Spence JD, Hegele RA: Differences between carotid wall morphological phenotypes measured by ultrasound in one, two and three dimensions. Atherosclerosis 2005; 178:319-325.

37 Lau DC, Dhillon B, Yan H, Szmitko PE, Verma S: Adipokines: molecular links between obesity and atheroslcerosis. Am J Physiol Heart Circ Physiol 2005;288:H2031-H2041.

-38 Beydoun MA, Beydoun HA, Wang Y: Obesity and central obesity as risk factors for incident dementia and its subtypes: a systematic review and meta-analysis. Obes Rev 2008;9:204-218.

39 Gustafson D: A life course of adiposity and dementia. Eur J Pharmacol 2008;585:163175 .

-40 Lange RT, Iverson GL, Zakrzewski MJ, Ethel-King PE, Franzen MD: Interpreting the trail making test following traumatic brain injury: comparison of traditional time scores and derived indices. J Clin Exp Neuropsychol 2005;27:897-906.

41 Perianez JA, Rios-Lago M, Rodriguez-Sanchez JM, Adrover-Roig D, Sanchez-Cubillo I, Crespo-Facorro B, Quemada JI, Barcelo F: Trail Making Test in traumatic brain injury, schizophrenia, and normal ageing: sample comparisons and normative data. Arch Clin Neuropsychol 2007;22:433-447.

42 Naismith SL, Hickie IB, Turner K, Little CL, Winter V, Ward PB, Wilhelm K, Mitchell P, Parker G: Neuropsychological performance in patients with depression is associated with clinical, etiological and genetic risk factors. J Clin Exp Neuropsychol 2003;25:866-877.

43 Oscar-Berman M, Marinkovic K: Alcohol: effects on neurobehavioural functions and the brain. Neuropsychol Rev 2007;17:239257.

44 Hester RL, Kinsella GJ, Ong B, McGregor J: Demographic influences on baseline and derived scores from the trail making test in healthy older Australian adults. Clin Neuropsychol 2005;19:45-54.

45 Tombaugh TN: Trail making test A and B: normative data stratified by age and education. Arch Clin Neuropsychol 2004;19:203214.

Fergenbaum/Bruce/Spence/Lou/Hanley/ Greenwood/Young 